Çukurova Üniversitesi Mühendislik Mimarlık Fakültesi Dergisi, 30(2), 183-189 ss., Aralık 2015

Çukurova University Journal of the Faculty of Engineering and Architecture, 30(2), pp. 183-189, December 2015

\title{
Türkiye İnşaat Endüstrisindeki İnovasyon Düzeyinin İnşaat Mühendisliği Penceresinden Görünümü
}

\author{
Olcay GENÇ ${ }^{* 1}$, Ayça BOZKURT ${ }^{1}$, Hilmi COŞKUN ${ }^{1}$, Ercan ERDİş ${ }^{1}$ \\ ${ }^{1}$ İskenderun Teknik Üniversitesi, İnşaat Fakültesi, İnşaat Mühendisliği Bölümü, İskenderun
}

Geliş tarihi: 27.10 .2015

Kabul tarihi:25.12.2015

\section{Özet}

İnovasyon; yeni veya önemli ölçüde değiştirilmiş ürün (mal ya da hizmet) veya sürecin; yeni bir pazarlama yönteminin; ya da iş uygulamalarında, iş yeri organizasyonunda veya dış ilişkilerde yeni bir organizasyonel yöntemin uygulanmasıdır. Bir ülkenin rekabet gücü, ülke endüstrilerinin yenilik ve gelişim yeteneğine, dolayısıyla inovasyona verdiği öneme bağlıdır. İnovatif organizasyonları olmayan toplumların gelişimleri sınırlı olup, bu toplumlar geri kalmaya ve yoksulluğa mahkûmdurlar. Ekonominin en can alıcı sektörü olan, başka bir deyişle de tüm sektörleri beraberinde tetiklediği için "Lokomotif Sektör" olarak adlandırılan inşaat sektörü, inovasyondan en hızlı etkilenmesi gereken sektörlerden birisidir. Her ne kadar diğer endüstriler inovasyonun önemi hakkında bir konsensüs oluşturmuş olsa da, inşaat sektörü inovasyonda ve inovasyon yönetiminde birleşmekte isteksizdir. Sektör bu yüzden sürekli olarak yenilikçi olmamak ve tutucu olmakla suçlanmıştır. Bu çalışmanın amacı, Türk inşaat sektöründe inovasyonun inşaat mühendisliği bazında yeterli düzeyde gerçekleşip gerçekleşmediğini, sektörün en çok hangi alanlarda inovatif uygulamalara ihtiyaç duyduğunu araştırmak, ayrıca sektör özelinde nelerin inovatif kapasiteyi artırabileceğini, inovasyonu olumsuz yönde etkileyen faktörleri ve inovasyon konusundaki AR-GE çalışmaları için sorumluluk alması gereken kurum ve kuruluşları tespit etmektir.

Anahtar kelimeler: İnovasyon, Yenilik, İnovatif, Türkiye inşaat endüstrisi

\section{The View of Innovation Level of Turkey' Construction Industry from Civil Engineering Window}

\begin{abstract}
Innovation is the implementation of new or significantly modified products (goods or services) or processes, new marketing method or the new organizationa 1 methods in business practices, workplace

\footnotetext{
* Yazışmaların yapılacağı yazar: Olcay GENÇ, İskenderun Teknik Üniversitesi, İnşaat Fakültesi, İnşaat Mühendisliği Bölümü, İskenderun, Hatay, genc_olcay@hotmail.com
} 
organization or external relations. The competitiveness of a country depends on the innovation and development capabilities of the country's industry hence to the importance given to innovation. While the development of non-innovative countries is limited, these countries are destined to remain poor and under-developed. The most crucial sector of the economy, which is called "the locomotive sector", in other words, triggering all the other sectors, the construction sector is one of the sectors to be affected by the rapid innovation. Although in other industries consensuses about the importance of innovation have been reached, the construction industry is reluctant to agree about innovation and innovation management. Because of that, the construction industry is accused of not being consistently innovative and of being conservative. The aims of this study are; to determine that in Turkish construction sector, the adequacy of innovation from civil engineering perspective; to find out which construction areas that need most of innovative practices and what can improve the innovative capacity; to learn about the factors that adversely affect innovation and; to identify the institutions and organizations which should take responsibility for innovation R \& D activities.

Keywords: Innovation, change, innovative, Turkish construction industry

\section{GíRiş}

Bilim ve teknoloji dünyasının son yıllarda en çok kullandığ1 kelimelerinden biri olan inovasyon İngilizce “'innovation" kelimesinden dilimize geçmiş olup; yenilik, değişiklik, yeni ve farklı fikirlerin yada uygulamaların ortaya atılması, yeni metot/alet, yeni şey anlamlarına gelmektedir. İnovasyonun ve türlerinin tanımına yönelik çok sayıda kaynak bulunmaktadır. İnovasyon kavramında, uluslararası kabul gören kaynak olarak OECD ile Avrupa Komisyonu'nun birlikte yayınladığı Oslo Kılavuzu temel alınmıştır. Tubitak tarafindan Türkçeye çevrilen Oslo Kılavuzu'na göre inovasyon; yeni veya önemli ölçüde değiştirilmiş ürün (mal ya da hizmet), veya sürecin; yeni bir pazarlama yönteminin; ya da iş uygulamalarında, işyeri organizasyonunda veya diş ilişkilerde yeni bir organizasyonel yöntemin uygulanması şeklinde tanımlanmıştır [1].

Bir ülkenin rekabet gücü, ülke endüstrilerinin yenilik ve gelişim yeteneğine dolayısıyla inovasyona verdiği öneme bağlıdır. İnovatif olmanın bir şirkete açık ödülleri vardır. Bunlar kaliteye ulaşmak, piyasada kalmak, büyümeyi, farklı olmayı ve kârlılı̆̆ı başarmaktır. İnovatif organizasyonları olmayan toplumların gelişimleri sınırlı olup, geri kalmaya ve yoksulluğa mahkumdurlar [2]. Birçok sektör ve çalışanları tarafindan bilincinde olunan bu kavramın faydaları; ülkenin ve toplumun kaynaklarının ürün ve hizmete dönüşmesi, bu ürün ve hizmetlerin ekonomik ve toplumsal kazanç sağlaması, sonucunda ise ekonomik büyüme ve toplumsal gelişmeye katkı olarak sıralanabilir [1]. İnovasyonlar etki gösterdiği pazarda farklı şekillerde etkilerini gösterebilirler. Bazen inovasyon, sahibi olan firmayı rakiplerinden farklı bir konuma taşır, bazen de firmanın içinde bulunduğu sektöre farklı bir bakış açısı getirip, artık sektörün yönünü farklı taraflara doğru çeker. $\mathrm{Bu}$ sebeple inovasyon çok yönlü özellikleri olan bir kavramdır [1]. İnovasyon, geriye dönmezlik özelliği de gösterir. Yeni ürün, eskisinin yerini aldığında, eski ürün pazarda tekrar görünmez. $\mathrm{Bu}$ durumun sebeplerinden biri, inovasyonun büyük bir performans ve maliyet avantajı sağlamasıdır. $\mathrm{Bu}$ nedenle, eski ürünün yeniden üretilmesi ekonomik olmaktan çıkar [3]. Yeni bir teknoloji kullanılmaya başlandığında, kullanıcıların bu teknolojiyi geliştirmesiyle, yeniliğin üzerine daha fazla bilgi üretmek olası hale gelecekken, eski teknoloji artık hiçbir kullanıcının karşılıklı etkileşimi olmadığından nispeten durgun kalacak, gelişemeyecektir. Örneğin buzdolabının buluşundan sonra, doğal yollardan buz yapımının, tekrar ortaya çıkması olası değildir. Ayrıca yeni ürün geliştirilmesinin, farklı bir teknoloji 
kullanımını gerektirmesi halinde yapılan sabit maliyetler, batık maliyete dönüşeceğinden eski ürün tekrar üretilmeyecektir [3].

Ekonominin en can alıcı sektörü olan, başka bir deyişle de tüm sektörleri beraberinde tetiklediği için "Lokomotif sektör" olarak adlandırılan inşaat sektörü, inovasyondan en hizlı etkilenmesi gereken sektörlerden birisidir [1]. Her ne kadar diğer endüstriler inovasyonun önemi hakkında bir konsensüs oluşturmuş olsa da, inşaat sektörü inovasyon ve inovasyon yönetiminde birleşmekte isteksizdir [2]. Yeniliğin nasıl başarıldı̆̆ı, yenilik sürecini neyin dürtüleyip neyin alıkoyduğu, endüstrinin spesifik özellikleri ve gelişimiyle çok ilişkilidir [4]. İnşaat endüstrisi bir takım çevreler tarafından sürekli olarak, yenilikçi olmamak ve tutucu olmakla suçlanmıştır. İnşaat endüstrisinde inovasyonun basarisini etkileyen bir kaç spesifik özellik vardır [5]. Önceki araştırmalar; mevzuatlar, yönetmelikler vb. iç özelliklerin inovasyonu teşvik etmek veya engellemede güçlü etkileri olduğunu göstermiştir [6].

Günümüzde, diğer sektörlerden farklı olarak inşaat alanında inovatif uygulamalar, proje seviyesinde gerçekleşmekte ve bu tür yenilikler üründen ziyade süreçsel ve kurumsal yenilikler olarak gözlemlenmektedir. Dolayısıyla, teknolojinin yoğun olduğu sektörlerden farklı özellikler gösteren inşaat sektöründeki inovasyonların da farklı göstergelerle ölçülmesi gerekmektedir [7].

İnşaat teknolojilerindeki yenilikler, geçmişte inşaat uygulamalarında etkileyici devrimlerle sonuçlanmıştır. Örneğin 1824'de Portland çimentosunun sektöre girmesi, beraberinde inşaat mühendisliği yöntemlerini tümüyle değiştirecek binlerce yeni inşaat teknolojisini sektöre getirdi. 20. yüzyılın ilk çeyreğinde çelik yapı teknolojisinin bulunup, sektöre kazandırılması inşaat teknolojilerindeki ikinci devrim dalgasını tetikledi. 1970'lerin sonlarında inşaat endüstrisinin verimliliğindeki düşüş, sektördeki yenilik anlayışının da önünü kesti [8]. İnşa edilebilirlik sorunları, prefabrikasyon, ve endüstrilerde yayılan otomatikleşme, birçok araştırmacıyı inşaat ve yönetim sisteminde yenilik arayışına itti [9].
Harcanan büyük çabaya rağmen sektördeki yenilikler, bu büyük arayışın yanında çok yavaş kaldı [10]. Ortak çalışmaların olmaması Halphin [11] tarafindan bu gecikmeye neden olarak gösterildi.

İnşaat endüstrisinde inovasyon çok zor ve sancılı bir süreçtir. $\mathrm{Bu}$ yüzden şirketler genelde bunun riskini almak istememektedirler. Yapılan çalışmalar göstermektedir ki, inşaat endüstrisinde; yeni fikirlere, değişiklik tekliflerine ve inovasyona karşı bir güven eksikliği vardır. Rekabetçilikte inovasyonun anahtar faktör olduğunu anlayamamalarından dolayı, inşaat şirketlerinin çoğu araştırma, geliştirme ve inovasyona yatırım yapmayı çekici bulmazlar [2].

Bu çalışmanın amacı, Türk inşaat sektöründe inovasyonun inşaat mühendisliği bazında yeterli düzeyde gerçekleşip gerçekleşmediğini, sektörün en çok hangi alanlarda inovatif uygulamalara ihtiyaç duyduğunu araştırmak, ayrıca sektör özelinde nelerin inovatif kapasiteyi artırabileceğini, inovasyonu olumsuz yönde etkileyen faktörleri ve inovasyon konusundaki ARGE çalışmaları için sorumluluk alması gereken kurum ve kuruluşları tespit etmektir.

\section{MATERYAL ve METOT}

Bu çalıșma, iki kısımdan oluşan web tabanlı bir anketin analizine yöneliktir. Anketin ilk kısmında; Türkiye inşaat sektöründe inovatif (yenilikçi) uygulamaların yeterli düzeyde gerçekleştirilip gerçekleştirilmediği, inşaat endüstrisinde inovatif (yenilikçi) uygulamaların en çok hangi alanda gerçekleştirilmesi gerektiği, inşaat sektöründe inovasyonu arttırmak için "yasal zorunluluk, standart veya teşvik getirilmesinin" üretkenlik anlamında inovasyonu geliştirip geliştiremeyeceği, geri dönüşüm-çevreye duyarlılık faktörünün inovatif kapasiteyi arttırıp arttırmayacağı, inşaat endüstrisinde müşteri beklentilerinin inovasyonda yönlendirici rol oynayıp oynamadığı, inşaatlarda iş güvenliğini sağlayan ürünlerin ve iş güvenliğini arttıran çözümlerin inovatif uygulamalarda artış sağlayıp sağlamayacağ bilgi teknolojisi ile desteklenen süreçler ve 
verimliliğin arttırılmasına yönelik yalın inşaat anlayışının, yenilikçi inşaat endüstrisi fikrine katkı sağlayıp sağlamayacağı, Türkiye inşaat sektöründe inovatif uygulamaları olumsuz yönde etkileyen faktörlerin neler olduğu, inovasyon ve Ar-Ge konusunda sorumluluk alması gereken kurum ve kuruluşların kimler olması gerektiği sorulmuş olup, anketin ikinci kısmı demografik sorulardan oluşmaktadır. Hazırlanan anket, meslek odaları vasıtasıyla Türkiye'nin çeşitli ilerinde kamu ve özel sektörde çalışan inşaat mühendislerine ulaştırılmıştır. Link, bir kişinin anketi birden fazla kez yanıtlamasını engellemek amaciyla her bilgisayarda yalnızca bir kez çalışacak şekilde programlanmıştır. Araştırmanın evreni Türkiye genelinde kamu ve özel sektörde çalışan inşaat mühendisleri olup, örnek uzayı ise 493 adet inşaat mühendisidir.

\section{ARAŞTIRMA BULGULARININ DEĞERLENDİRİLMESİ}

Çalışmanın bulgular kısmı, inşaat mühendislerinin Türkiye inşaat sektöründe inovasyonun düzeyinden memnun olup olmadıkları, inşaat alanında en çok hangi alanlarda inovatif uygulamalara ihtiyaç duydukları, nelerin inovatif kapasiteyi artırabileceğini öngördükleri, neleri inovasyonu olumsuz yönde etkileyen faktörler olarak tanımladıkları ve inovasyonun AR-GE çalışmaları için öngördükleri sorumluluk alması gereken kurum ve kuruluşların tespiti ile ilgili anket sonuçlarının değerlendirilmesi ve yorumlanmasından oluşmaktadır.

Çizelge 1. İnşaat sektöründe yenilikçi uygulamaların yeterlilik düzeyi

\begin{tabular}{lc|c}
\hline Katılımcıların inşaat & \multicolumn{2}{c}{ Verilen Cevapların } \\
sektöründeki yenilikçi & Frekans1 ve Yüzdesi \\
\cline { 2 - 3 } $\begin{array}{l}\text { uygulamaları yeterli } \\
\text { bulup/bulmama durumu }\end{array}$ & $\mathrm{f}$ & $\%$ \\
\hline Evet yeterli buluyorum & 71 & 14,4 \\
Hayır yeterli bulmuyorum & 407 & 82,6 \\
Fikrim yok & 15 & 3,0 \\
\hline
\end{tabular}

Çizelge 1 incelendiğinde ankete katılan inşaat mühendislerinin çok büyük çoğunluğu $(\% 82,6)$, inşaat sektöründeki yenilikçi uygulamaların yeterli düzeyde gerçekleşmediği görüşündedir. \%14,4 katılımcı sektördeki inovatif uygulamaları yeterli bulurken \%3,0 katılımcı fikrinin olmadığını söylemiştir.

Çizelge 2. İnşaat endüstrisinde yenilikçi uygulamaların gerekli olduğu alanlar

\begin{tabular}{|c|c|c|}
\hline \multirow{2}{*}{$\begin{array}{l}\text { İnşaat endüstrisinde } \\
\text { inovatif (yenilikçi) } \\
\text { uygulamaların en çok } \\
\text { gerçekleştiği alanlar }\end{array}$} & \multicolumn{2}{|c|}{$\begin{array}{l}\text { Verilen Cevapların } \\
\text { Frekansı ve Yüzdesi }\end{array}$} \\
\hline & $\mathrm{f}$ & $\%$ \\
\hline Proje - Tasarım & 140 & 28,4 \\
\hline Malzeme & 134 & 27,2 \\
\hline Üretim - İmalat & 149 & 30,2 \\
\hline İş Güvenliği & 70 & 14,2 \\
\hline
\end{tabular}

Çizelge 2'de inşaat mühendislerinin endüstride en çok hangi alanda yenilik ihtiyacı duydukları verilmiştir. En az $(\% 14,2)$ inovatif uygulama ihtiyacı olan alan iş güvenliği alanı olarak belirtilirken, üretim-imalat $(\% 30,2)$, proje-tasarım $(\% 28,4)$ ve malzeme $(\% 27,2)$ alanları birbirine yakın oranları ile en çok yenilik ihtiyacı olan alanlar olarak gösterilmiştir.

Çizelge 3. Yasal zorunluluk, standart veya teşvikin inovasyona katkıs1

\begin{tabular}{lc|c}
\hline $\begin{array}{l}\text { İnşaat sektöründe yasal } \\
\text { zorunlulukların, standartların } \\
\text { geliştirilmesinin ve yatırıma } \\
\begin{array}{l}\text { teşviğin üretkenlik anlamında } \\
\text { inovasyonu geliştirme düzeyi }\end{array}\end{array}$ & \multicolumn{2}{c}{$\begin{array}{c}\text { Verilen } \\
\text { Cevaplarn } \\
\text { Frekans1 ve } \\
\text { Yüzdesi }\end{array}$} \\
\cline { 2 - 3 } Evet Geliştirebilir & 426 & $\%$ \\
Hayır Geliştiremez & 54 & 11,0 \\
Fikrim yok & 13 & 2,6 \\
\hline
\end{tabular}

Çizelge 3 incelendiğinde katılımcıların \%86,4'ü inşaat sektöründe inovasyonu arttırmak için yasal zorunluluk, standart veya teşvik getirilmesini, 
üretkenlik anlamında inovasyonu geliştirebilir bulurken, \%11,0 katılımcı aynı fikirde değildir.

Çizelge 4. Geri dönüşüm - çevreye duyarlılık faktörünün inovasyona etkisi

\begin{tabular}{lc|c}
\hline $\begin{array}{l}\text { Geri dönüşüm -çevreye } \\
\text { duyarlılık faktörünün } \\
\text { inovatif kapasiteyi } \\
\text { artırıp/artırmayacağı }\end{array}$ & \multicolumn{2}{c}{\begin{tabular}{c}
\multicolumn{2}{c}{ Verilen Cevapların } \\
Frekansı ve Yüzdesi
\end{tabular}} \\
\cline { 2 - 3 } Evet & 419 & $\%$ \\
Hayır & 53 & 10,8 \\
Fikrim yok & 21 & 4,3 \\
\hline
\end{tabular}

Çizelge 4 incelendiğinde ankete katılanların \%85,0 gibi büyük bir kısmının, geri dönüşüm-çevreye duyarlılık faktörünü inovatif kapasiteyi artırır olarak gördüğü, \%10,8'nin ise bu görüşe katılmadığı görülmektedir.

Çizelge 5. Müşteri beklentilerinin inovasyondaki rolü

\begin{tabular}{lc|c}
\hline Katılımcıları, inşaat & \multicolumn{1}{c}{$\begin{array}{c}\text { Verilen } \\
\text { endüstrisinde müşteri } \\
\text { beklentilerinin inovasyonda } \\
\text { etkili olup/olmadığı } \\
\text { yönündeki düşünceleri }\end{array}$} & $\begin{array}{c}\text { Cevapların } \\
\text { Frekansı ve } \\
\text { Yüzdesi }\end{array}$ \\
\cline { 2 - 3 } Evet düşünüyorum & $\mathrm{f}$ & $\%$ \\
\hline Hayır düşünmüyorum & 358 & 72,6 \\
Fikrim yok & 124 & 25,2 \\
\hline
\end{tabular}

Çizelge 5 incelendiğinde inşaat mühendislerinin \%72,6'sinin müşteri beklentilerinin inşaat endüstrisinde inovasyonda yönlendirici rol oynayacağını düşündüğü görülmektedir. Katılımcıların \%25,2'si bu şekilde düşünmezken $\% 2,2$ 'lik kısım fikir beyan etmemiştir.
Çizelge 6. İş güvenliğinin inovasyona etkisi

\begin{tabular}{lc|c}
\hline $\begin{array}{l}\text { İnşaatlarda iş güvenliğini } \\
\text { sağlayan ürünlerin ve iş } \\
\text { güvenliğini arttıran }\end{array}$ & \multicolumn{2}{c}{$\begin{array}{l}\text { Verilen } \\
\text { Cevapların }\end{array}$} \\
$\begin{array}{l}\text { çözümlerin inovatif } \\
\text { uygulamalarda artış }\end{array}$ & \multicolumn{2}{c}{$\begin{array}{l}\text { Frekansı ve } \\
\text { Yüzdesi }\end{array}$} \\
\cline { 2 - 3 } $\begin{array}{l}\text { sağlayıp/sağlamama } \\
\text { durumu }\end{array}$ & $\mathrm{f}$ & $\%$ \\
\hline & & \\
Evet düşünüyorum & 355 & 72,0 \\
Hayır düşünmüyorum & 112 & 22,7 \\
Fikrim yok & 26 & 5,3 \\
\hline
\end{tabular}

Çizelge 6 incelendiğinde, inşaat mühendislerinin \%72,0'si iş güvenliği için kullanılan kişisel ve toplu koruyucu ürünler vb. ve iş güvenliğini arttırmak için geliştirilen çözümlerin inovatif uygulamalarda artış sağlayacağına katılmaktadırlar.

Çizelge 7. Yalın inşaatın inovasyona katkısı

\begin{tabular}{lc|c}
\hline Tam zamanında üretim vb. & \multicolumn{2}{c}{$\begin{array}{c}\text { Verilen } \\
\text { bilgi teknolojisi ile } \\
\text { desteklenen süreçler ve } \\
\text { verimliliğin arttırılmasına }\end{array}$} \\
$\begin{array}{l}\text { yönelik yalın inşaat } \\
\text { anlayışının yenilikçi inşaat } \\
\text { endüstrisi fikrine katkı }\end{array}$ & \multicolumn{2}{c}{$\begin{array}{c}\text { Frekansı ve } \\
\text { Yüzdesi }\end{array}$} \\
\cline { 2 - 3 } sağlayıp/sağlamama durumu & & $\%$ \\
& & \\
Evet & 370 & 75,1 \\
Hayır & 71 & 14,4 \\
Fikrim yok & 52 & 10,5 \\
\hline
\end{tabular}

Çizelge 7 incelendiğinde katılımcıların \%75,1'inin tam zamanında üretim vb. bilgi teknolojisi ile desteklenen süreçler ve verimliliğin arttırılmasına yönelik yalın inşaat anlayışının inşaat sektöründeki inovasyon fikrine katkı sağlayacağ1 görüşündeyken, \%14,4 ayni fikirde değildir. \%10,5 katılımcı ise bu konuda fikrinin olmadığını belirtmiştir. 
Çizelge 8. İnşaat sektöründe inovasyonu yönlendirecek teknolojiler

\begin{tabular}{lc|c}
\hline $\begin{array}{l}\text { Yenilikçiliği en fazla } \\
\text { etkileyen inşaat } \\
\text { teknolojileri }\end{array}$ & \multicolumn{2}{c}{$\begin{array}{c}\text { Verilen Cevapların } \\
\text { Frekansı ve Yüzdesi }\end{array}$} \\
\cline { 2 - 3 } & $\mathrm{f}$ & $\%$ \\
\hline $\begin{array}{l}\text { Yeşil Binalar - Eko } \\
\text { Binalar }\end{array}$ & 278 & 56,4 \\
$\begin{array}{l}\text { Nanoteknoloji } \\
\text { Yalın İnşaat - Tam }\end{array}$ & 118 & 23,9 \\
Zamanında Üretim & 97 & 19,7 \\
\hline
\end{tabular}

Çizelge 8 incelendiğinde katılımcıların \%56,4'u yeni teknolojilerden Yeşil Binalar- Eko Binaların inşaat sektöründe yenilikçiliğgi en fazla yönlendirmesi gerektiğini düşünürken, $\% 23,9$ 'u Nanoteknolojiyi, \%19,7'si ise yalın inşaat-tam zamanında üretimi inovasyonu yönlendirmesi gereken yeni teknolojiler olarak görmüşlerdir.

Çizelge 9. İnşaat sektöründe inovasyonun önündeki engeller

\begin{tabular}{lc|c}
\hline $\begin{array}{l}\text { Sektörde inovatif } \\
\text { uygulamaları olumsuz } \\
\text { yönde etkileyen faktörler }\end{array}$ & \multicolumn{2}{c}{$\begin{array}{c}\text { Verilen Cevapların } \\
\text { Frekansı ve Yüzdesi }\end{array}$} \\
\hline & $\mathrm{f}$ & $\%$ \\
\hline & & \\
Finansal Yetersizlik & 92 & 18,7 \\
$\begin{array}{l}\text { İnovasyon Bilincinin } \\
\text { Gelişmemiş Olması }\end{array}$ & 270 & 54,8 \\
$\begin{array}{l}\text { Nitelikli İ̧ Gücü } \\
\text { Yetersizliği }\end{array}$ & 131 & 26,6 \\
\hline
\end{tabular}

Çizelge 9'da Türkiye inşaat sektöründe inovatif uygulamaları olumsuz yönde en fazla etkileyen faktörler görülmektedir. Katılımcıların \%54,8'ine göre inovasyon bilincinin gelişmemiş olması faktörü ilk sırayı alırken, bunu \%26,6 ile nitelikli iş gücü yetersizliği ve $\% 18,7$ ile finansal yetersizlik takip etmiştir.
Çizelge 10. İnovasyon ve $\mathrm{Ar}-\mathrm{Ge}$ konusunda sorumluluk alması gerekenler

\begin{tabular}{|c|c|c|}
\hline \multirow{2}{*}{$\begin{array}{l}\text { İnovatif kapasiteyi } \\
\text { arttırmada en fazla } \\
\text { sorumluluk alan } \\
\text { kurum/kuruluşlar } \\
\end{array}$} & \multicolumn{2}{|c|}{$\begin{array}{c}\text { Verilen Cevapların } \\
\text { Frekansı ve Yüzdesi }\end{array}$} \\
\hline & $\mathrm{f}$ & $\%$ \\
\hline Devlet & 204 & 41,4 \\
\hline Üniversiteler & 126 & 25,6 \\
\hline Özel Sektör & 163 & 33,1 \\
\hline \multicolumn{3}{|c|}{$\begin{array}{l}\text { Çizelge } 10 \text { incelendiğinde inşaat mühendislerinin } \\
\% 41,4 \text { 'ü inovasyon ve AR-GE konusunda inovatif } \\
\text { kapasiteyi arttırmak için en fazla sorumluluğu } \\
\text { devletin almas1 gerektiğini düşünürken, \%33, '’ } \\
\text { özel sektörün, \%25,6's1 ise üniversitelerin bu } \\
\text { sorumluluğu üstlenmesi görüş̧ündedir. }\end{array}$} \\
\hline
\end{tabular}

\section{SONUÇLAR VE ÖNERİLER}

Amac1, Türk inşaat sektöründe inovasyonun inşaat mühendisliği bazında yeterli düzeyde gerçekleşip gerçekleşmediğinin, inşaat alanında en çok hangi alanların inovatif uygulamalara ihtiyaç duyduğunun, nelerin inovatif kapasiteyi artırabileceğinin, inovasyonun olumsuz yönde etkileyen faktörlerin ve inovasyon AR-GE çalışmaları için sorumluluk alması gereken kurum ve kuruluşların tespiti olan bu çalışmada, konu ile ilgili Türkiye genelinde özel ve kamu sektöründe çalışan 493 inşaat mühendisinin görüşlerine başvurulmuştur. Elde edilen sonuçlar 1şı̆̆ı̀nda, Türk inşaat sektörünün inovasyon konusunda yetersiz olduğu, devletin inovasyon ve AR-GE konusunda sektöre öncülük etmesi gerektiği, bunun için gerekirse yasal zorunluluk ve standartların oluşturulması ve nihayetinde sektörde bir inovasyon bilinci uyandırılmasının gerekliliğine kanaat getirilmiştir. Türkiye'de bugün ve gelecekte sektörün inovatif uygulamaları şeklinde nitelendirilebilecek yenilikçi yaklaşımlar şu şekilde sıralanabilir:

- İnşaat sektöründe çok fazla ürün ve ham madde kaynaklarının kullanımının azaltılmasına yönelik teknikler, 
- İnşaat sektöründeki düşük verimliliğin arttırılmasına yönelik süreç ve metotsal gelişmeler; yalın inşaat, tam zamanında inşaat (just in time) $v b$,

- Enerji, çevre ve sürdürülebilirlik konularında getirilen standartlar, zorunluluklar, yasal düzenlemeler ve artan tüketici bilinci,

- Enerji verimliliği odaklı ve çevreye duyarlı, daha az kaynak kullanımına dönük teknikler ve geri dönüştürülebilir ürün bazlı yenilikler,

- Yeşil bina, sıfır karbon salınıml1-sıfır enerjili binalar, eko-binalar,

- İnşaatlarda iş güvenliğini sağlayan ürünler ve iş güvenliğini arttıran çözümler,

- Nanoteknoloji, biyoteknoloji, akıllı malzeme ve sistemler,

- İnşaat esnasında ortaya çıkan atıklara bağlı olarak geliştirilen/geliştirilecek atık yönetimi ve geri dönüşüm,

- Nitelikli iş gücü eksikliğini azaltmak için inovasyon kapsamında teorik ve pratik eğitimler.

\section{TEŞEKKÜR}

Anket çalışmamıza verdiği katkılardan dolayı İMO İstanbul Şubesi'ne teşekkürü bir borç biliriz

\section{KAYNAKLAR}

1. Fiş, G., 2010. İnşaat Sektöründe Inovasyon, Yüksek Lisans Tezi, İstanbul Teknik Üniversitesi, İstanbul, 89p.

2. Serpell, A., Alvarez, R., 2014. A Systematic Approach for Evaluating Innovation Management in Construction Companies, Procedia Engineering, 85: 464-472.

3. Jorde, T., Teece, D., 1989. Competition and Cooperation: Striking the Right Balance, California Management Review, 25-37.

4. Abernathy, W., Utterback, J., 1978. Patterns of Innovation in Technology, Technology Review, 80(7): 40-47.

5. Bygballe, L. E., Ingemansson, M., 2014. The Logic of Innovation in Construction. Industrial Marketing Management, 43: 512-524.

6. Blayse, A.M., Manley, K., 2004. Key
Influences on Construction Innovation, Construction Innovation, 4(3): 143-154.

7. Bozkurt, A., Coşkun, H., Erdiş, E., 2014. Avrupa Birliği İçinde Türkiye İnşaat Sektörünün Yenilikçilik Kapasitesi, 3. Proje ve Yapım Yönetimi Kongresi, 6-8 Kasım.

8. Yu, W., Cheng, S., Wu, C., Lou, H., 2012. A Self-Evolutionary Model for Automated İnnovation of Construction Technologies, Automation in Construction, 27: 78-88.

9. O'Connor, J. T., Miller, S. J., 1994. Constructability Programs: Method for Assessment and Benchmarking, Journal of Performance of Constructed Facilities, ASCE, 8(1): 46-64.

10. Yang, L. R., O'Connor, J.T., Chen, J. H., 2007. Assessment of Automation and Integration Technology's Impacts on Project Stakeholder Success, Automation in Construction, 16(6): 725-733.

11. Halpin, D. W., 1993. Process-Based Research to Meet the International Challenge, Journal of Construction Engineering and Management, ASCE, 119(3): 417-425. 
